\title{
Exploring the spatiotemporal behavior of Helsinki's housing prices with fractal geometry and cointegration.
}

\section{Votsis, Athanasios}

2017-04

Votsis , A 2017 , ' Exploring the spatiotemporal behavior of Helsinki's housing prices with fractal geometry and cointegration. ' , Journal of Geographical Systems , vol. 19 , no. 2 , pp. 133-155 . https://doi.org/10.1007/s10109-017-0247-0

http://hdl.handle.net/10138/235549

https://doi.org/10.1007/s10109-017-0247-0

unspecified

acceptedVersion

Downloaded from Helda, University of Helsinki institutional repository.

This is an electronic reprint of the original article.

This reprint may differ from the original in pagination and typographic detail.

Please cite the original version. 


\title{
Exploring the spatiotemporal behavior of Helsinki's housing prices with fractal geometry and co-integration
}

\section{(C) Springer Science+Business Media New York 2017, published in the Journal of Geographical Systems at https://link.springer.com/article/10.1007/s10109-017-0247-0}

This is the Final Draft version of the article for self-archiving purposes, according to Helsinki University's Open Access policy and the Publisher's self-archiving rules.

\section{Athanasios Votsis ${ }^{1,2}$}

${ }^{1}$ Socio-economic Impact Research, Finnish Meteorological Institute, Erik Palménin Aukio 1, PO Box 503, FI-00101, Helsinki, Finland, athanasios.votsis@ fmi.fi

${ }^{2}$ Department of Geosciences and Geography, University of Helsinki, Helsinki, Finland

\begin{abstract}
Fractal geometry and co-integration are combined for exploring spatial morphological aspects of quarterly dwelling prices in Helsinki's region from 1977 to 2011 . Curves of fractal scaling behavior are first employed to measure the fractal dimensions of high and low price $/ \mathrm{m}^{2}$ spatial clusters at multiple scales. Subsequently, the fractal dimensions at indicative neighborhood and citywide scales are modeled with vector error correction specifications. The results identify long run joint equilibria between the fractal geometries of high and low price $/ \mathrm{m}^{2}$ clusters at both spatial scales. High price/ $\mathrm{m}^{2}$ clusters exhibit consistently higher fractal dimensions than their low value counterparts at the neighborhood scale, while this long run relation is reversed at the citywide scale. Short run disequilibria and subsequent adjustments are also scale sensitive. The fractal geometry of high price $/ \mathrm{m}^{2}$ clusters leads the dynamics at the neighborhood scale, while low price $/ \mathrm{m}^{2}$ clusters lead at the citywide scale. The system's responses to exogenous shocks take longer time to stabilize at the neighborhood scale compared to the citywide scale, but in both scales the non-stationary nature of fractal behavior is evident. These elements indicate that a closer look on spatial economic behavior at more than one spatial and temporal scale at a time can reveal nontrivial information in the context of urban research and policy analysis.
\end{abstract}

Keywords: fractals; co-integration; residential property value; multiscale dynamics

JEL codes: R12; R31; C62; C63

Funding: This research was funded by the Academy of Finland (decision number 140797 for project RECAST) and the Helsinki University Centre for Environment (HENVI project ENSURE).

Acknowledgments: Parts of an earlier version of this article were presented in the 2013 Applied Urban Modelling symposium at the University of Cambridge and the author is thankful for comments received by the participants. The invaluable comments and guidance of three anonymous reviewers is also acknowledged. 


\section{Introduction}

The spatial variation of residential real estate value is widely used as an indicator in understanding the impacts of urban planning interventions (e.g., Perino et al. 2014; Votsis and Perrels 2016) and as an element in modeling the flows and interactions of an urban economy's spatial equilibrium (e.g., Wegener 1994; Anas 2013; Echenique et al. 2013). Moreover, differentiating between areas of high and low property prices is a typical step in understanding and modeling urban growth and land use (Brueckner et al. 1999; O’Sullivan 2000; Brueckner 2011).

Housing prices are formed and driven by multiple equilibria and by processes that operate at more than one spatial and temporal scales. Hedonic price theory (Rosen 1974; Dubin 1988; Sheppard 1999; DiPasquale and Wheaton 1996) and the Alonso-Muth-Mills (AMM) family of models (Alonso 1964; Mills 1967; Muth 1969) are microeconomic approaches that explain the formation and differentiation of residential property prices, but they also contain unaddressed issues with respect to spatial and temporal behavior. Firstly, each approach refers to processes that are particular to one spatial scale. The AMM approach is a citywide aggregate model that derives property prices from the location behavior of firms and households in relation to transport costs, distance to the city center, and the geographical configuration of amenities (Brueckner et al. 1999). In contrast, hedonic price theory refers to a buyer-seller matching process and decomposes realized market prices into implicit prices of a spatial vector of structural, locational, and neighborhood attributes of the properties themselves. An economic theory that approaches residential property prices across spatial scales is not available, although multiscale spatial economic analysis is a growing field (Batty 2007; Wegener 2008; Ioannides 2013). Secondly, although the AMM model implies that in the long run a stable spatial configuration of property prices is established - as part of a city's spatial equilibrium (see e.g., O’Sullivan 2000, Glaeser and Gottlieb 2009, Brueckner 2011) — short run volatility is a typical feature of housing prices as empirical time series and hedonic studies show. Elaborating on these short run dynamics and their relationship to the long run spatial equilibrium is particularly relevant for the time scales in which urban planning, decision-making, and several of the issues they aim to address are operating.

This paper aims to explore empirically multiple spatial and temporal scales together, by approaching the geographical behavior of housing prices as a time series. The study's focus is not on the underlying factors of housing price formation and differentiation and its adjustments; the interest is instead on the long and short run spatial characteristics of housing prices as realized in urban space at multiple spatial scales. The approach is inspired by time series macroeconometrics and may illuminate less-studied but important aspects of urban economic behavior. Two particular spatiotemporal aspects are of interest: the geographical behavior of housing prices at more than one spatial scale (i.e., a more elaborate view of space), and the interplay between long run equilibrium and short run out-of-equilibrium spatial processes (i.e., more details in temporal behavior).

Equilibrium can have multiple meanings, depending on the process being modeled. In this paper, the notion of equilibrium is empirical and relates to the long run spatial configuration of high and low property prices. Out-of-equilibrium behavior is understood here as quarterly volatilities and adjustments (of spatial configuration of housing prices) around the long run equilibrium. The concurrent look at equilibria and disequilibria is backed by research in agent-based economics (Filatova et al. 2009; Ettema 2011; Filatova and Bin 2013) and by time series studies of land value and property prices (Kenny 1999; Oikarinen 2005, 2014; Saarinen 2013). Moreover, the specifics of 
in- and out-of-equilibria processes are expected to vary at different spatial scales, as cities are increasingly shown to contain multiscale processes (Batty and Longley 1994; Batty 2007).

These aspects are explored using housing prices in the metropolitan region of Helsinki in the period between 1977 and 2011. The aim of analyzing multiscale spatial behavior motivates the use of fractal geometry and in particular the curves of fractal scaling behavior, which represent a nonEuclidean understanding of geographical space. The aim of studying the interplay between in- and out-of-equilibrium behavior motivates the use of the concept of co-integration and the estimation of vector error correction models. The co-integration analysis of the fractal behavior of property prices captures the volatile behavior of property prices in space and time as a process that underlies an overly stable spatial equilibrium at the micro and macro scales.

\section{Methodology}

Fractals are mathematical sets, the visualization of which produces complex shapes that are selfsimilar across scales of magnification (Mandelbrot 1967, 1982). In the case of spatial scales, a fractal entity fills space in a self-replicating manner, and this property of self-affinity has been utilized in urban studies to explore growth processes of the built environment and characterize its spatial morphology (Batty and Longley 1994; Batty 2007).

Various methods are available for estimating the fractal dimension. This study uses grid counting. Assume a binary image of a geographical object, with black pixels representing the object and white pixels otherwise. Let a square frame with edge length $\varepsilon$ count the number of black pixels $N$ that fall inside its perimeter, and repeat the procedure by increasing $\varepsilon$ at specified intervals and recounting $N$. From the multiple counts of $N$ at various increments of $\varepsilon$, we can estimate $N$ as a function of $\varepsilon$ and include an adjustment factor $\alpha$ (Frankhauser 1998; Thomas et al. 2008, 2012), so that:

$$
N(\varepsilon)=\alpha \varepsilon^{D}
$$

$D$ corresponds to the fractal dimension and ranges from zero to two. $D=0$ indicates a mass concentrated at a single point, $D<1$ is a scattered/disconnected pattern of clusters ('dust'), $D>1$ is a connected pattern of clusters ('carpet') and $D=2$ is a uniformly scattered mass.

It can be further assumed that fractal dimension $D$ depends on scale $\varepsilon$ (Thomas et al. 2010). This happens when the spatial morphology of an entity exhibits sharp changes from one scale to another,

as in the transition from single buildings to building blocks, neighborhoods, and larger zones. Varying $D$ with $\varepsilon$ produces the curve of fractal scaling behavior (CFSB), which is a sequence of fractal dimensions that characterizes a sequence of scales, so that fractal behavior across a continuum of scales is simultaneously assessed. The CFSB has been used to identify critical scales at which fractal behavior (i.e., spatial morphology) changes significantly and as detailed signatures of particular types of urban morphologies (Batty 2001; Thomas et al. 2010). Frankhauser (1998) and Thomas et al. (2010) derive Eq. (2) from Eq. (1) that describes the CFSB

$$
\frac{\mathrm{d} \log [N(\varepsilon)]}{\mathrm{d} \log (\varepsilon)} \equiv A(\varepsilon)=\frac{\mathrm{d} \log [\alpha(\varepsilon)]}{\mathrm{d} \log (\varepsilon)}+\frac{\mathrm{d} D(\varepsilon)}{\mathrm{d} \log (\varepsilon)} \log (\varepsilon)+D(\varepsilon)
$$


The CFSB series can be volatile and if exhibiting non-stationarity, the concept of co-integration is particularly useful. This concept originates from time series econometrics and is frequently used in macroeconomic analysis. Its basic idea is the estimation of the relationship between at least two nonstationary time series over time $t$. Such series pose challenges to standard estimation methods. Often a variable that is non-stationary in its levels becomes stationary when considering its differences at times $t$ and $t$ - $d$, where $d$ denotes temporal distance. Depending on the value of $d$ that is needed to render the variable's differenced series stationary, the variable is referred to as integrated nonstationary of order $d$, or $I(d)$.

In certain cases, the linear combination of two or more non-stationary integrated variables produces a stationary time series. In particular, if variables $x$ and $y$ are integrated of order $d$, and a linear combination of them is integrated of order $d$-l, then $x$ and $y$ are co-integrated of order $l$. This suggests that although a number of variables can fluctuate (quasi)randomly over time, a linear combination of them can be stationary. The Granger-Engle representation theorem (Engle and Granger 1987) states that if $x$ and $y$ are co-integrated, they will have an error correction representation, where the error correction term is their co-integration relationship.

Johansen $(1988,1991,1995)$ proposed to analyze the co-integrating relationship in a multiequation setting by using a $K$-variable second order vector autoregressive (VAR) model, representing a class of multivariate, multi-equation autoregressive time series models. Johansen's approach uses a VAR model as the basis to estimate and interpret the endogenous dynamics between non-stationary series, and the resulting model is called the vector error correction (VEC) model. The model considers the levels, differences, and lags of a vector of co-integrated variables and estimates their stationary linear combination, referred to interchangeably as the co-integrating behavior, co-integrating relationship, or long run (joint) equilibrium relationship, and the more immediate volatile behavior around the equilibrium, referred to as the short run adjustment behavior. Additional vectors of trend parameters can be included to the short and long run relationships, producing the VEC equation given by

$$
\Delta \boldsymbol{y}_{t}=\boldsymbol{\gamma}+\boldsymbol{\tau} t+\boldsymbol{\alpha}\left(\boldsymbol{\beta}^{\prime} \mathbf{y}_{t-1}+\boldsymbol{v}+\boldsymbol{\rho} t\right)+\sum_{i=1}^{p-1} \boldsymbol{\Gamma}_{i} \Delta \boldsymbol{y}_{t-i}+\boldsymbol{u}_{t}
$$

In Eq. (3), $\boldsymbol{y}_{t}$ is a $K \times 1$ vector of $I(1)$ co-integrated variables that have $r$ co-integrating relationships in the range $0<r<K, \Delta$ denotes first differences, $\boldsymbol{\gamma}$ and $\boldsymbol{\tau}$ are $K \times 1$ vectors of trend parameters, $\boldsymbol{v}$ and $\boldsymbol{\rho}$ are $r \times 1$ vectors of trend parameters, $\boldsymbol{\alpha}$ and $\boldsymbol{\beta}$ are $K \times r$ coefficient vectors, the prime symbol (') denotes the transpose operator, $p$ is the order of the underlying VAR model, $\boldsymbol{\Gamma}_{i}$ is the sum of the $K \times K$ coefficient matrices of the underlying $p$-order VAR, and $\boldsymbol{u}_{t}$ is a $K \times 1$ vector of i.i.d. disturbances with zero mean and covariance matrix $\boldsymbol{\Sigma}_{u}$.

The parameter estimate, $\widehat{\beta}$, of $K \times r$ vector $\boldsymbol{\beta}$ is the co-integrating relationship of the variables in $\boldsymbol{y}_{t}$ and provides information about their long run equilibrium relationship. For the case of the present study, the long run relationship of two co-integrated variables $y_{1}$ and $y_{2}$ with one co-integrating relationship yields a $2 \times 1$ vector $\boldsymbol{\beta}$. The parameter estimate $\widehat{\beta}=[1, \beta]$ provides the linear combination of the two variables, i.e., $y_{1}+\beta y_{2}=0$, which is stationary and called the co-integrating equation (CE). The parameter estimate, $\widehat{\alpha}$, of $K \times r$ vector $\alpha$ provides information about the short run behavior of the 
co-integrated system, estimating the speeds of adjustment to the joint equilibrium after periods of disequilibrium.

While the co-integrating equation represented by $\boldsymbol{\beta}$ and the adjustment coefficients represented by $\boldsymbol{\alpha}$ provide basic intuitions about system behavior, further interpretation of the dynamics of the system represented by Eq. (3) is facilitated by impulse response analysis. Impulse responses track the responses of a variable in vector $\boldsymbol{y}$ to impulses from another variable in $\boldsymbol{y}$, assuming that the impulse is caused by a shock that is exogenous to the modeled system. Eq. (3) is an autoregressive process and can be re-written in a moving average (MA) form, in which $\boldsymbol{y}_{t}$ is explained by a series of $i$ temporally lagged disturbances $\boldsymbol{u}_{t}$ with $K \times J$ coefficient matrix $\boldsymbol{\Phi}_{i}$. The $j k^{\text {th }}$ element of $\boldsymbol{\Phi}_{i}, \varphi_{k j, i}$, is the impulse response of the $j^{\text {th }}$ variable of Eq. (3) to a unit shock in the $k^{\text {th }}$ variable of Eq. (3) $i$ time periods in the past (Lütkepohl 2005). A graph of $\varphi_{k j, i}$ as a function of $i$ is called the impulse response function (Hamilton 1994). This formulation assumes that the responses of the system to shocks in one of its variables occur in an uncorrelated manner and holding everything else constant. As Lütkepohl and Krätzig (2004) note, it is more reasonable to assume that shocks do not occur in isolation when the elements of $\boldsymbol{u}_{t}$ in Eq. (3) are correlated, that is, when its covariance matrix $\boldsymbol{\Sigma}_{u}$ is not diagonal. To address this, i.e., to reflect the instantaneous nature of changes in the system of Eq. (3), orthogonal impulse responses are calculated as $\boldsymbol{\Theta}_{i}=\boldsymbol{\Phi}_{i} \boldsymbol{P}$, with $\boldsymbol{P}$ being a matrix of the Choleski decomposition of $\boldsymbol{\Sigma}_{u}$ so that $\boldsymbol{\Sigma}_{u}=\boldsymbol{P} \boldsymbol{P}^{\prime}$. As previously, the $j k^{\text {th }}$ element of $\boldsymbol{\Theta}_{i}, \theta_{k j, i}$, is the orthogonal impulse response of the $j^{\text {th }}$ variable of Eq. (3) to a unit shock in the $k^{\text {th }}$ variable of Eq. (3) that occurred $i$ time periods in the past, taking into account the instantaneous changes in variables across the system. A graph of $\theta_{k j, i}$ as a function of $i$ is the orthogonalized impulse response function (OIRF) for a particular impulseresponse pair of variables in $\boldsymbol{y}$.

The complete mathematical representation of impulse responses is extensive and can be found in Hamilton (1994, 318-323), Lütkepohl and Krätzig (2004, 165-171), and Lütkepohl (2005, 51-63). Further details about VEC and their underlying VAR models are found in Hamilton (1994), Lütkepohl and Krätzig (2004) and Lütkepohl (2005). It should be noted that the econometric framework of VEC models does not typically include exogenous variables. They rather focus on endogenous dynamics between non-stationary variables. It is important to note that the application of VEC models in this paper enables to focus on the endogenous relationship between the spatial morphological characteristics of price clusters over time and across spatial scales.

\section{Assumptions}

The first assumption made is that, although the AMM and hedonic price models are typically seen as static, their intuited geographical configuration of low and high housing prices in a city can be regarded as overly stable and referred to as an empirical long run equilibrium. As discussed in Section 1, this is in line with the practice of referring to the land use, firm and household location, land rent, and property price patterns of an urban area as a spatial equilibrium. The second assumption is that high and low price clusters do not exhibit a stable morphology when considering shorter time frames, but a variable one due to fluctuations in factors such as supply and demand, macroeconomic conditions, and shifts in market preferences and sentiments. In other words, short run adjustments do not only refer to market prices, but their spatial realization as well. The third assumption is that short run and long run behavior can be empirically modeled as co-dependent, and that the particular parameters of this relationship are sensitive to spatial scale. 
As previously discussed, two non-stationary series can have a stationary linear combination, and this provides a framework for examining the in- and out-of-equilibrium spatial economic behavior in relation to each other. Allowing Eq. (2) to vary by time and price category yields

$$
\left\{\frac{\mathrm{d} \log [N(\varepsilon)]}{\mathrm{d} \log (\varepsilon)}\right\}_{w t} \equiv A(\varepsilon)_{w t}=\left\{\frac{\mathrm{d} \log [\alpha(\varepsilon)]}{\mathrm{d} \log (\varepsilon)}\right\}_{w t}+\left\{\frac{\mathrm{d} D(\varepsilon)}{\mathrm{d} \log (\varepsilon)}\right\}_{w t} \log (\varepsilon)+D(\varepsilon)_{w t}
$$

with $w$ denoting the type of spatial cluster \{high value; low value $\}$ and $t$ time. Assuming that Eq. (4) produces two co-integrated time series, and inserting $D(\varepsilon)_{w t}$ in Eq. (3) gives

$$
\left[\begin{array}{l}
\Delta D(\varepsilon)_{\mathrm{high}} \\
\Delta D(\varepsilon)_{\mathrm{low}}
\end{array}\right]_{t}=\boldsymbol{\gamma}+\boldsymbol{\tau} t+\boldsymbol{\alpha}\left(\boldsymbol{\beta}^{\prime}\left[\begin{array}{l}
D(\varepsilon)_{\mathrm{high}} \\
D(\varepsilon)_{\mathrm{low}}
\end{array}\right]_{t-1}+\boldsymbol{v}+\boldsymbol{\rho} t\right)+\sum_{i=1}^{p-1} \boldsymbol{\Gamma}_{i}\left[\begin{array}{l}
\Delta D(\varepsilon)_{\mathrm{high}} \\
\Delta D(\varepsilon)_{\mathrm{low}}
\end{array}\right]_{t-i}+\boldsymbol{u}_{t}
$$

Eq. (5) enables the co-integration analysis of the fractal behavior of low and high price clusters.

\section{Data, spatial aggregation, and cluster identification}

The analysis uses a sample of approximately 300,000 housing transactions, which record the selling price of properties in the metropolitan region of Helsinki (Helsinki City and its adjoining suburban municipalities of Espoo and Vantaa). The transactions cover the period between 1977 and 2011 and are voluntarily collected by a consortium of Finnish real estate brokers and refined and maintained by VTT (Valtion Teknillinen Tutkimuslaitos) Technical Research Centre of Finland Ltd.

The selling prices were de-trended by adjusting for inflation with 2011 as the reference year and normalized to EUR thousand per square meter by dividing the selling price of each property by its floor space as indicated in its transaction record. The implication of price adjustment for the subsequent analysis is that the prices of each year are made comparable as they all refer to 2011 levels; high and low prices $/ \mathrm{m}^{2}$ as well as the derived spatial clusters have a common baseline. Persquare-meter price normalization clears interfering factors, notably the size and type of dwelling, from the comparison of prices across the study area.

The observations were spatially aggregated in a $100 \times 100 \mathrm{~m}$ lattice. Exploratory spatial autocorrelation tests indicated that clusters of about 50 to $200 \mathrm{~m}$ return the strongest spatial autocorrelation in property prices, so that a $100 \mathrm{~m}$ cell can be taken as a homogenous area as far as property price is concerned. A quarterly temporal resolution was chosen to capture the temporal behavior of property prices in reasonable detail. This produced 135 lattices of transaction realizations in space, from 1977Q2 to 2011Q4. The starting time period of the analysis is 1977Q2, because 1977Q1 contains an insufficient amount of observations. The cells of each lattice were classified into statistically significant high and low price/ $\mathrm{m}^{2}$ clusters by employing the Getis-Ord Gi* statistic (Getis and Ord 1992; Ord and Getis 1995). The significance upon which the clusters were identified was adjusted for multiple testing and spatial dependence using the false discovery rate correction method (Caldas de Castro and Singer 2006). Cells found as hot spots at $90 \%$ significance or better were classified as high price $/ \mathrm{m}^{2}$ clusters, and cells identified as cold spots at the $90 \%$ or better significance 
level were classified as low price $/ \mathrm{m}^{2}$ clusters. The influence of aggregation and clustering choices in the estimated results is further discussed in Section 6.

Fig. 1 displays examples of the clusters for three indicative years. The top row shows all realized dwelling transactions and the middle and bottom rows depict high and low price $/ \mathrm{m}^{2}$ clusters. The images indicate that the produced high and low price $/ \mathrm{m}^{2}$ cells are consistent with the residential property price gradient as predicted in the spatial equilibrium of the AMM model and with empirical hedonic studies: high price clusters are observed near the city center and low price clusters in the urban periphery.

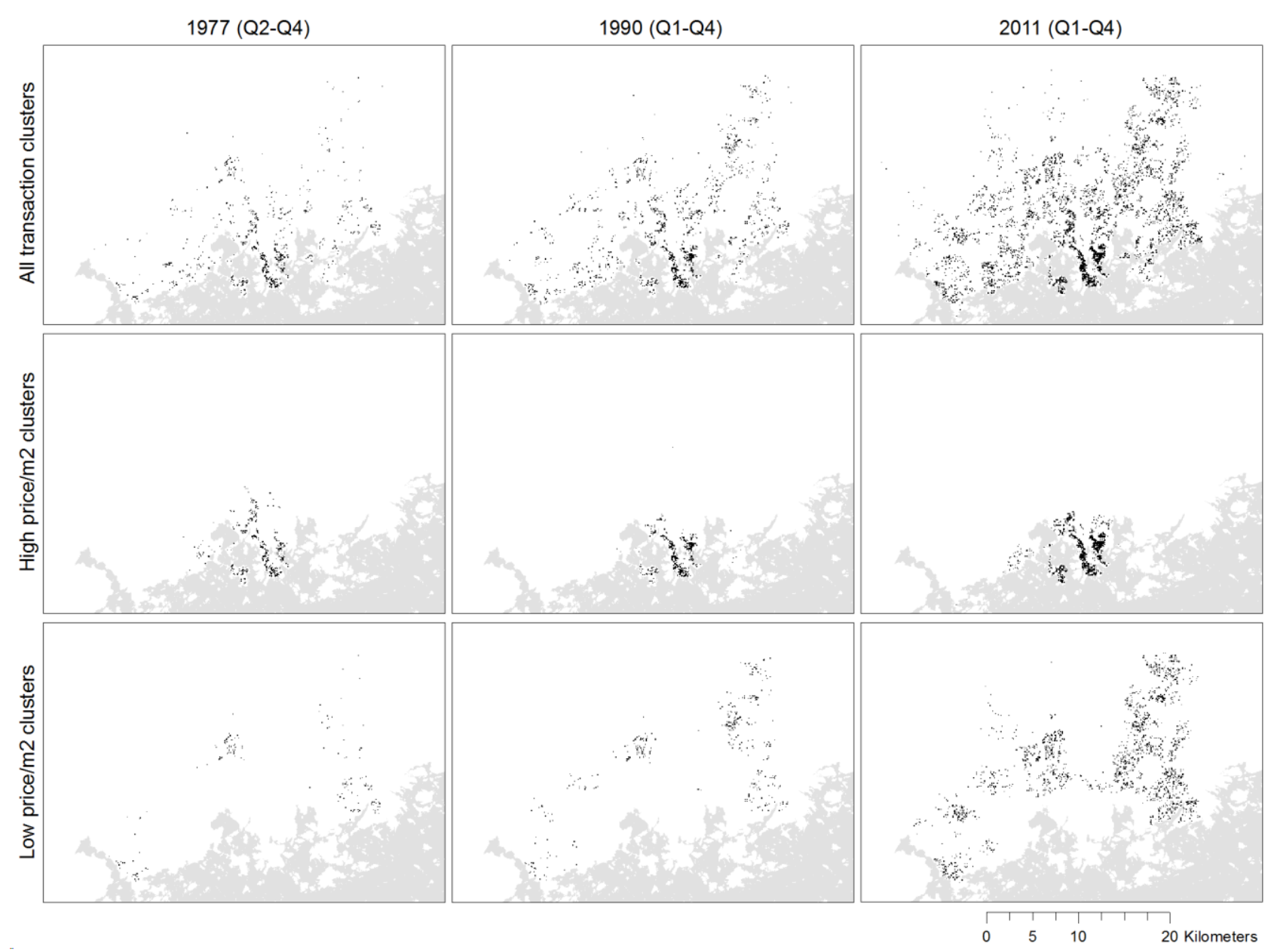

Fig. 1 Examples of the analyzed lattices

\section{Results}

This section firstly discusses the CFSB estimated for high and low price $/ \mathrm{m}^{2}$ clusters. The results of the co-integration analysis of the quarterly time series of fractal dimensions at the spatial scales of $200 \mathrm{~m}$ and 12,800 $\mathrm{m}$ are discussed afterwards. The section concludes by summarizing the results and discussing their main implications.

\subsection{The estimated curves of fractal scaling behavior}

The algorithms used to estimate Eq. (4) were provided by the tool 'Fractalyse' (City, mobility, territory research group at ThéMA, Université de Franche-Comté and Université de Bourgogne), and 
the clusters of high and low price $/ \mathrm{m}^{2}$ were calculated in ESRI ArcMap. Fig. 2 displays the decadal progression in the scaling behavior of high and low price $/ \mathrm{m}^{2}$ clusters.

The curves indicate that the fractal dimensions of the spatial clusters of both price categories have steadily increased between years 1977 and 2011 at the scales of 100 to 6,400 m, while the reverse is observed at the scale of $12,800 \mathrm{~m}$, notably in the high price category. In the low price $/ \mathrm{m}^{2}$ category, the gradual increase in fractal dimensions is concurrent with a flattening of the scaling curve, which translates to the gradual elimination of sharp changes in cluster morphology across scales, especially at $6,400 \mathrm{~m}$. The scaling behavior in the high price $/ \mathrm{m}^{2}$ category exhibits a similar smoothening between years 1977 and 1999, but sharp changes at 6,400 m re-emerge after year 2000. An additional point of notice is that in both price $/ \mathrm{m}^{2}$ categories, the scale of $6,400 \mathrm{~m}$ exhibits a gradual transition from fractal dimensions below one to dimensions over one, which is the limit of disconnected/connected morphology. Overall, the critical character of scales $800 \mathrm{~m}$ (or $800 \mathrm{~m}-1,600$ $\mathrm{m}$ ) and 6,400 $\mathrm{m}$ is largely preserved throughout the four-decade period.
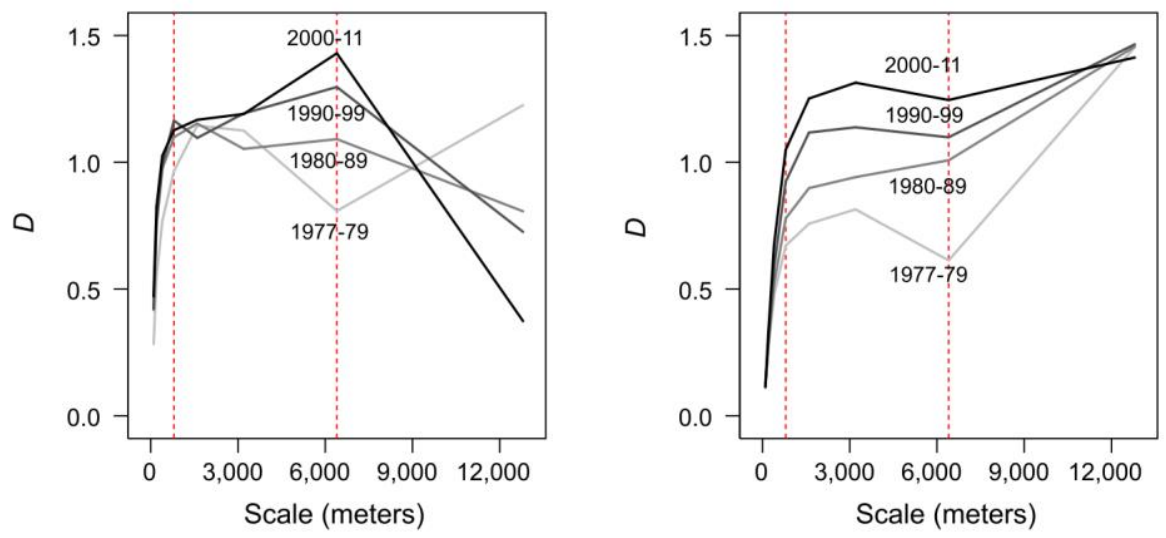

Fig. 2 Scaling behavior at decadal intervals of high (left) and low (right) price $/ \mathrm{m}^{2}$ clusters

The temporal behavior of the fractal dimensions of individual scales is clearer when the horizontal axis is used to represent time measured in quarters rather than distance (see Fig. 3). This lets the various curves at the same graph represent time series of fractal dimensions for each spatial scale.

It is possible to group the fractal evolution of different spatial scales into three sets: (a) micro scale behavior measured at the spatial scales of $100 \mathrm{~m}, 200 \mathrm{~m}$, and $400 \mathrm{~m}$; (b) meso scale behavior measured at the spatial scales of $800 \mathrm{~m}, 1,600 \mathrm{~m}$, and 3,200 m; and (c) macro scale behavior at 6,400 and $12,800 \mathrm{~m}$. This distinction echoes the critical scales of $800 \mathrm{~m}$ and 6,400 $\mathrm{m}$ discussed previously, and the main distinguishing factors are short run temporal volatility and the long run difference between the fractal dimensions of low and high price $/ \mathrm{m}^{2}$ categories. As scales progress from the micro towards the macro level, one can observe an increase in the volatility of the time series and a concurrent change in the relative magnitude of the fractal dimensions of the two price $/ \mathrm{m}^{2}$ categories. The volatility in the high price category is remarkable at the macro scales, with fractal dimensions registering across most of the spectrum of possible values (0-1.5 or 0.5-2). Curves in various scales exhibit obvious alternations between dimensions less than one and over than one. Long run equilibria around which the quarterly volatility takes place is also evident at all scales. A formal methodology 
for grouping and comparing curves of fractal scaling behavior has been proposed by Thomas et al. (2010), but has not been employed here, as the intuitions gained from Fig. 3 provide sufficient exploratory capacity in preparation of formal analysis with vector error correction models.

The CFSB encourages the idea that a separation of spatial scales will reveal non-trivial information, since there are critical transitions in spatial behavior when moving from the micro-scale towards the macro scale. Furthermore, the temporal structure in the fractal dimensions appears to depend on both scale and price cluster. The following section formally explores these assertions by estimating vector error correction models at micro and macro spatial scales.
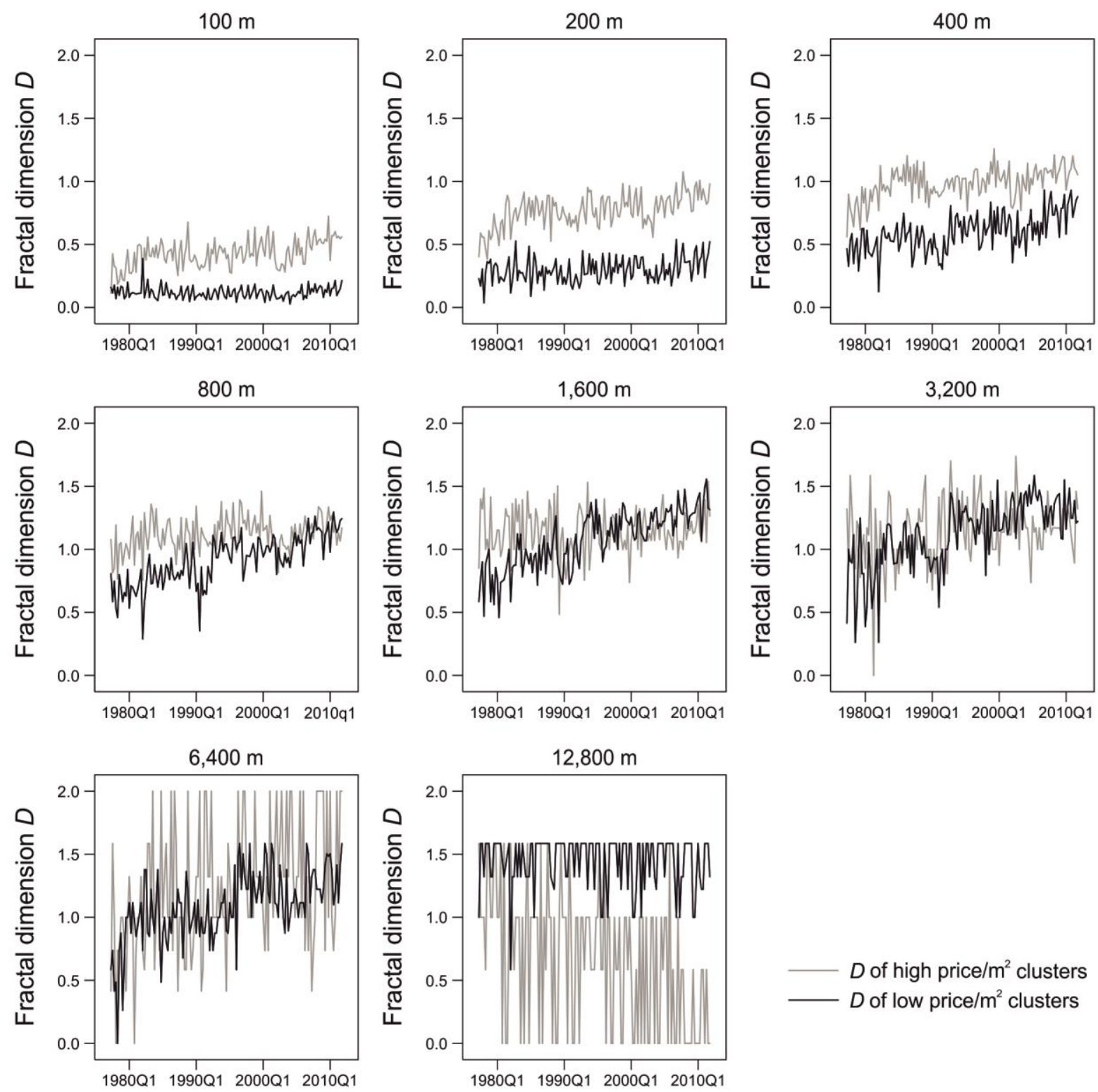

$D$ of high price $/ \mathrm{m}^{2}$ clusters

Fig. 3 Time series of the fractal dimension $(D)$ of high and low price/ $\mathrm{m}^{2}$ clusters at eight spatial scales

\subsection{Co-integration analysis}

The intuition behind applying co-integration analysis to fractal dimension time series is that the fractal dimensions of high and low value clusters, in addition to their characteristics as individual time series, 
are engaged in a joint long run equilibrium relationship. Deviations due to the short run volatility of high and low value clusters do not last indefinitely. The morphologies of each price category adjust to recover the long run equilibrium. As explained in Section 2, the joint equilibrium is an empirical concept that helps to understand how one variable responds to fluctuations of its co-integrated pair.

The fractal dimensions of high and low value clusters at $\varepsilon=200 \mathrm{~m}$ and $\varepsilon=12,800 \mathrm{~m}$ (see Fig. 4) were selected as representatives for the micro scale and macro scale, respectively. The former corresponds to a neighborhood of a few building blocks and the latter is approximately 1.5 the radius of the urban area, with six sub-regions covering most of the area. Fig. 5 illustrates the two scales. The analysis was conducted in STATA 13.1. The hypothesis of a unit root in the level variables cannot be rejected by the augmented Dickey-Fuller (ADF) and modified Dickey-Fuller with generalized least squares (DF-GLS) $t$-tests, whereas it can be rejected for their first differences at the $99 \%$ confidence interval. The inference is that the fractal dimensions at both scales are non-stationary integrated $I(1)$ series, i.e., that while the variables themselves are non-stationary, their first differences are stationary.

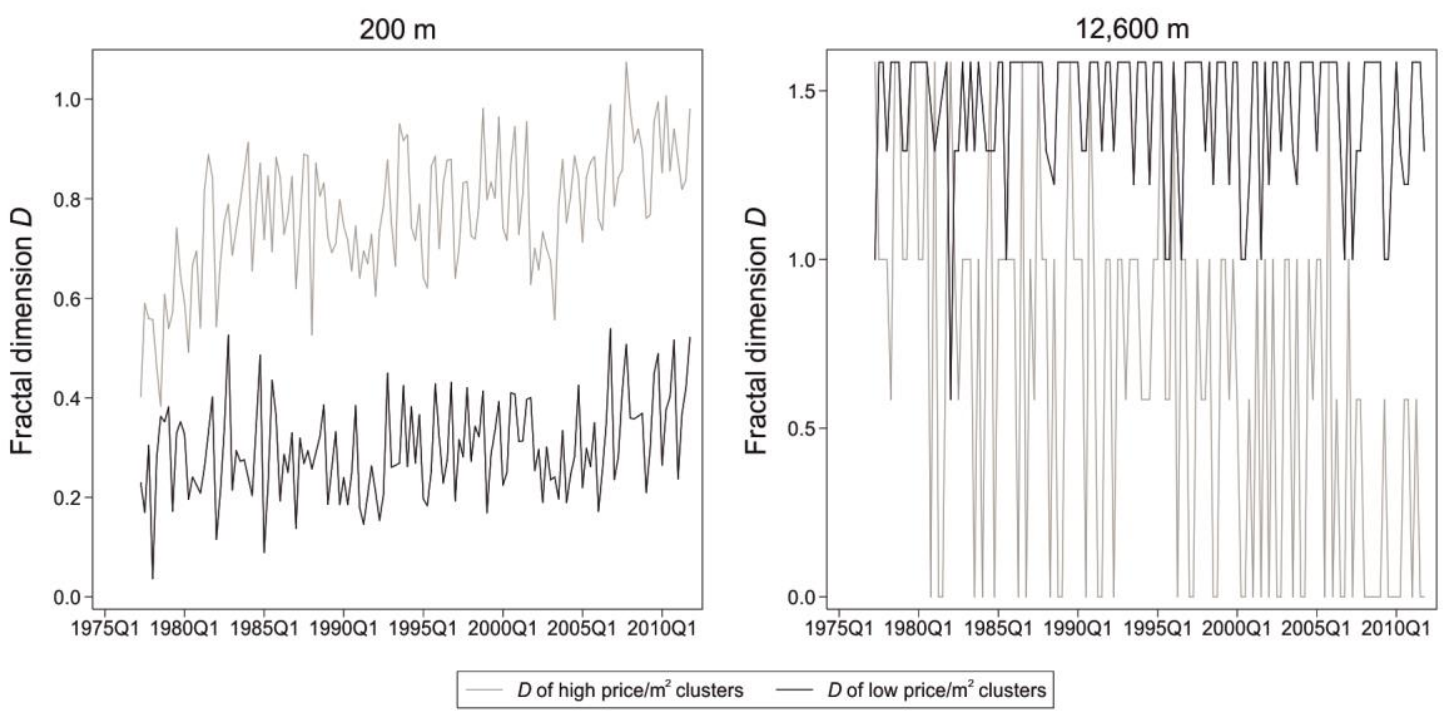

Fig. 4 Fractal time series at the spatial scales of $200 \mathrm{~m}$ (left) and 12,800 m (right)
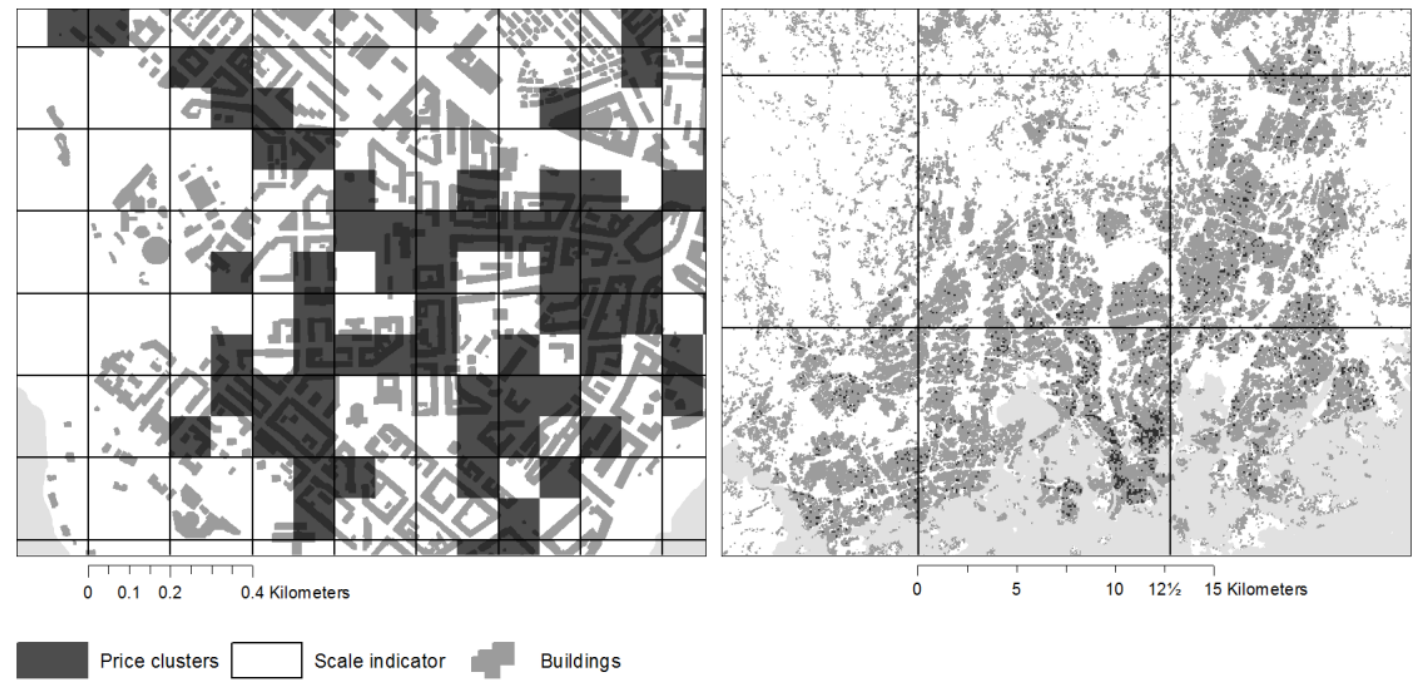

Fig. 5 The analyzed price $/ \mathrm{m}^{2}$ clusters at the scales of $200 \mathrm{~m}$ (left) and 12,800 m (right) 
Since each individual fractal time series is non-stationary first order integrated, pairs of them at each spatial scale can be tested for co-integration. Eq. (5) was fitted to the fractal dimensions of high and low price clusters at scales $\varepsilon=200 \mathrm{~m}$ and $12,800 \mathrm{~m}$. Information criteria searched for a plausible lag order $p$-indicating four lags for the models at both scales — and for confirming the logical expectation of one co-integrating relationship per two variables at each scale. It was decided to restrict the trend vectors $\gamma, \boldsymbol{\tau}, \boldsymbol{v}$ and $\boldsymbol{\rho}$ of Eq. (5) to zero, assuming that this exclusion of trends will not misrepresent the modeled dynamics. This assumption was verified by post-estimation tests. Drawing from the assumption of residential location models that high bidders initiate the process of residential location sorting, the variable order was set to high value cluster followed by low value cluster at each scale. Table 1 summarizes the main components of the estimation process.

Table 1 Estimated VEC parameters

\begin{tabular}{|c|c|c|}
\hline & (a) Micro scale $(\varepsilon=200 \mathrm{~m})$ & (c) Macro scale $(\varepsilon=12,800 \mathrm{~m})$ \\
\hline Number of lags $(p)$ & $p=4$ & $p=4$ \\
\hline Trend assumptions & $\tau=\rho=\gamma=\nu=0$ & $\tau=\rho=\gamma=\nu=0$ \\
\hline Time frame & 1977Q2-2011Q4 & 1977Q2-2011Q4 \\
\hline No. of obs. & 139 & 139 \\
\hline $\begin{array}{l}\text { Co-integrating parameter vector }(\widehat{\beta}) \\
(p \text {-value })\end{array}$ & $\begin{array}{l}{[1,-2.578]} \\
(n / a, 0.000)\end{array}$ & $\begin{array}{l}{[1,-0.441]} \\
(n / a, 0.000)\end{array}$ \\
\hline $\begin{array}{l}\text { Adjustment speeds }(\widehat{\alpha}) \\
(p \text {-value })\end{array}$ & $\begin{array}{c}{[-0.079,0.263]} \\
(0.378,0.000)\end{array}$ & $\begin{array}{c}{[-0.565,0.003]} \\
(0.000,0.960)\end{array}$ \\
\hline
\end{tabular}

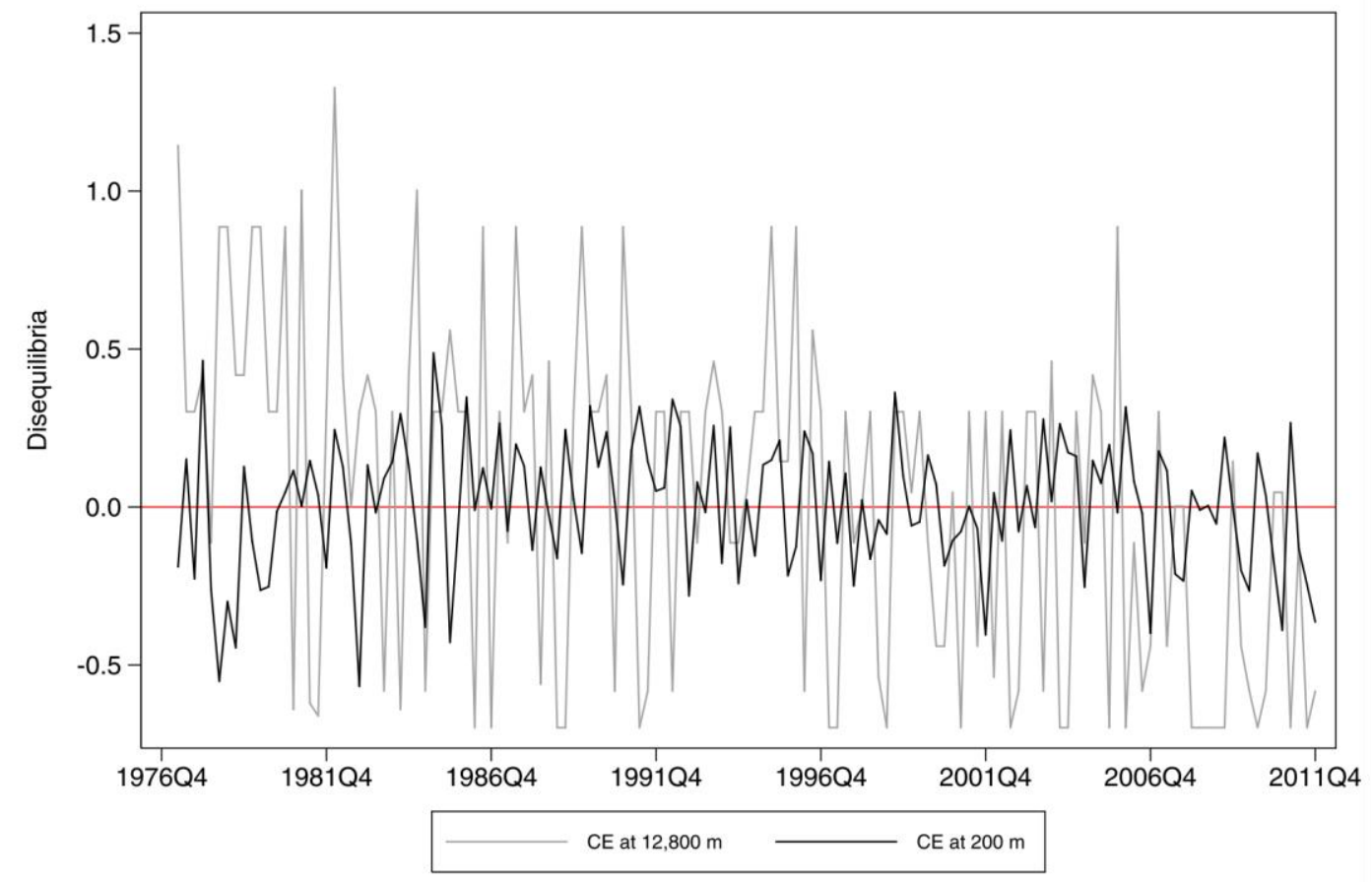

Fig. 6 Estimated co-integrating equations (CE), representing deviations from the joint equilibrium at the spatial scales of $200 \mathrm{~m}$ and $12,800 \mathrm{~m}$ 
Deviations from the joint equilibrium of each scale can be traced in the corresponding cointegrating equation (CE) (see Fig. 6). The CEs show that, during the four decades under investigation, deviations from the equilibrium morphologies have been largely contained within $+/-$ 0.5 fractal units at the scale of $200 \mathrm{~m}$ and within -0.7 and +0.9 at $12,800 \mathrm{~m}$.

The information criteria for the model at $\varepsilon=200 \mathrm{~m}$ supported a fourth order VEC model (four lags) with one co-integrating relationship for the assumed restrictions $\boldsymbol{\tau}=\boldsymbol{\rho}=\boldsymbol{\gamma}=\boldsymbol{v}=0$. The parameter estimate, $\widehat{\beta}$, of the long run equilibrium relationship is given as $[1,-2.578]$ and is highly significant. The parameter estimate, $\widehat{\alpha}$, of the adjustment coefficients is $[-0.079,0.263]$ and only that of low value clusters is significant, while the adjustment of high value clusters is insignificant. The parameter estimate of $\beta$ indicates that the long run equilibrium at the micro scale is characterized by a high value to low value cluster ratio of 2.6 in terms of their fractal dimensions, as also indicated by Fig. 4 (left), which translates to a consistently higher fractal dimension of high value clusters compared to that of low value clusters. In disequilibrium periods, the statistically insignificant adjustment coefficient of high value clusters suggests that when the fractal dimension of high value clusters deviates from its equilibrium, it does not tend to adjust back. This indicates a lead role for high value clusters in the overall dynamics. At the same time, low value clusters will tend to adjust in order to restore the joint equilibrium shown in the co-integrating equation at $200 \mathrm{~m}$ in Fig. 6. In these disequilibrium situations, the co-integrating equation implied by $\widehat{\beta}$ shows that a one-unit change in the fractal dimension of high value clusters will lead to an approximately 0.39-unit change in that of low value clusters. Concerning the role of temporal lags, the fractal dimension of high price clusters is significantly influenced by its own values in past quarters but not by the past values of low price clusters, while the fractal dimension of low price clusters is influenced by the past values of both high and low price clusters. This reaffirms the indication that high price clusters lead the dynamics at the micro scale.

The orthogonal impulse responses explore the impact of a one-time shock of a variable in a cointegrated system on the other variables of the system and on itself (see Section 2). Fig. 7 presents the orthogonalized impulse response functions (OIRFs) for the estimated VEC model at the spatial scale of $200 \mathrm{~m}$. There is a clear self-reinforcing feedback in high value clusters, i.e., a recursive additive response of the fractal dimension of high value clusters to its own change. Shocks in the fractal dimension of high value clusters induce an immediate positive response of about 0.1 fractal units and this reinforcing stabilizes to about 0.04 after 20 quarters (Fig. 7a). The response of low value clusters to impulses from high value clusters is also positive, starting at about 0.03 fractal units and stabilizing to about 0.02 units after 20 quarters (Fig. 7b). On the other hand, the self-reinforcing feedback in low value clusters is subdued relative to the corresponding feedback in their high value counterparts, with the effects stabilizing at about 0.01 fractal units after 20 quarters (Fig. 7c). The response of high value clusters to impulses from low value clusters starts at about 0.075 fractal units and fades to zero after 20 quarters (Fig. 7d). Overall, the OIRFs of Fig. 7 suggest that high value clusters drive the system at the spatial scale of $200 \mathrm{~m}$. Exogenous shocks in the fractal dimension of high value clusters induce greater and permanent impacts across the system, while low value clusters have subdued, near-transient or transient effects. This is in line with the lead role of high value clusters that is discerned from the estimates of the adjustment coefficients $\alpha$. Weak occasional negative impulse responses during the first quarters following an exogenous shock are also present (Fig. 7bd), but are questionable due to the unavailability of standard error estimates. 
(a)

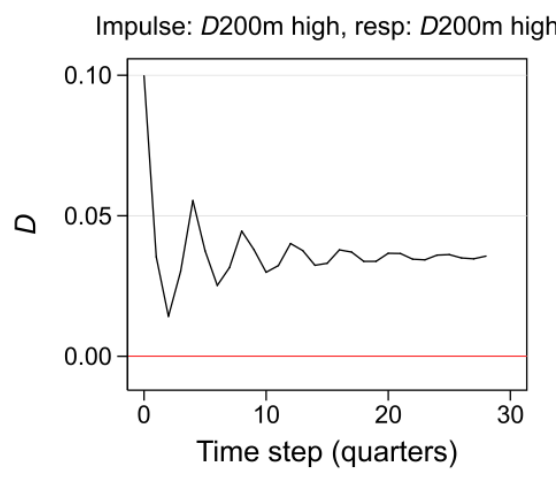

(c)

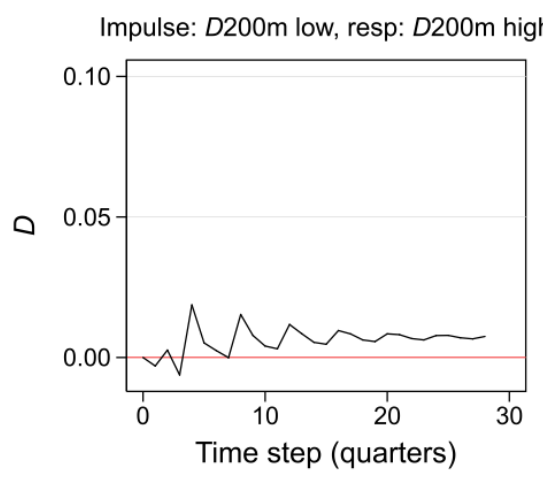

(b)

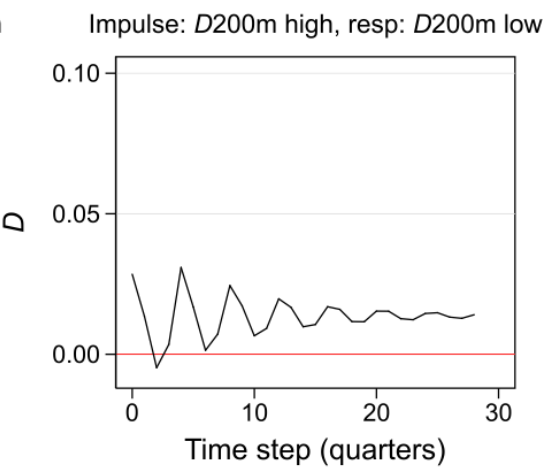

(d)

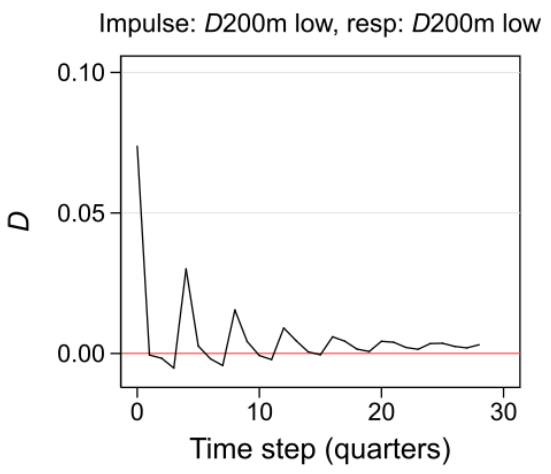

Fig. 7 Orthogonal impulse responses at micro scale $\varepsilon=200 \mathrm{~m}$ : (a) response of high value $D$ to impulse of high value $D$, (b) response of low value $D$ to impulse of high value $D$, (c) response of high value $D$ to impulse of low value $D$, and (d) response of low value $D$ to impulse of low value $D$

The model at $\varepsilon=12,800 \mathrm{~m}$ was fitted as a fourth order VEC model with the restrictions $\boldsymbol{\tau}=\boldsymbol{\rho}=$ $\boldsymbol{\gamma}=\boldsymbol{v}=0$. The tests support the expected number of one co-integrating relationship. The estimations returned a highly significant parameter vector $\widehat{\beta}=[1,-0.441]$ for the long run relationship. The estimates of the adjustment coefficients, $\widehat{\alpha}$, are given by $[-0.565,0.003]$ with only the adjustment of high value clusters being significant. These results suggest that the long run equilibrium is characterized by a high to low value cluster ratio of 0.4 in terms of their fractal dimensions. This indicates that, as a rule, high value clusters exhibit a consistently lower fractal dimension than their low value counterparts (see also Fig. 4 right). This is a reversal of the results at the micro scale. In periods when the fractal dimension of low value clusters is above or below its equilibrium, it will not tend to adjust. During these periods, high value clusters will tend to adjust in order to restore the joint equilibrium shown in the co-integration equation at $12,800 \mathrm{~m}$ of Fig. 6 . These elements indicate a lead role for low value clusters in the citywide dynamics. The parameter estimate of $\boldsymbol{\beta}$ shows that during disequilibria, a one-unit change in the fractal dimension of low values will induce an approximately 0.44-unit change in the fractal dimension of high value clusters. Compared to the scale of $200 \mathrm{~m}(0.39)$ this is a slightly higher 'elasticity'. Concerning the role of temporal lags, the fractal dimension of high price clusters is significantly influenced by its own values in past quarters and by the most recent quarter of low price clusters, while the fractal dimension of low price clusters is only influenced by its past quarters. This supports the idea that low price clusters are the leads in the dynamics of this scale. 
The suggested lead role for low value clusters at the citywide scale is the reverse of what is found at the neighborhood scale, but potentially conflicts with the assumed variable order. To further check this, a VEC model with the alternate variable order (fractal dimension of low value clusters followed by that of high value clusters) was estimated and indicated the same dynamics. The estimations returned a highly significant parameter estimate, $\widehat{\beta}=[1,-2.270]$, outlining an identical long run relationship as above (the inverse coefficients since the order of variables is swapped), an insignificant adjustment coefficient for low value clusters, and a highly significant adjustment coefficient for high value clusters.

The OIRFs presented in Fig. 8 indicate that the macro scale dynamics are driven chiefly by shocks in the fractal dimension of low price clusters. Changes in the fractal dimension of low value clusters appear to induce permanent effects in the system, while their high value counterparts induce near transient effects. These elements indicate a reversal from the micro scale. In particular, the selfreinforcing feedback in low value clusters starts at 0.2 fractal units and stabilizes to 0.1 after ten quarters (Fig. 8d), while the response of high value clusters to impulses from low value clusters, exempting initial oscillations, is relatively stable at 0.05 units after eight quarters (Fig. 8c). The selfreinforcing feedback in high value clusters starts rather strongly at 0.5 fractal units, but drops rapidly in the next quarters, reaching to zero after about ten quarters (Fig. 8a). The response of low value clusters to impulses from high value clusters starts at 0.1 units and stabilizes to near zero after eight quarters (Fig. 8b). As with the model at the micro scale, the indications of negative impulse responses are rather weak.

(a)

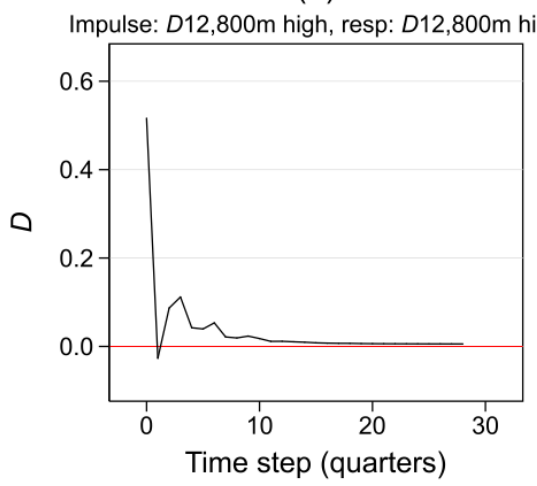

(c)

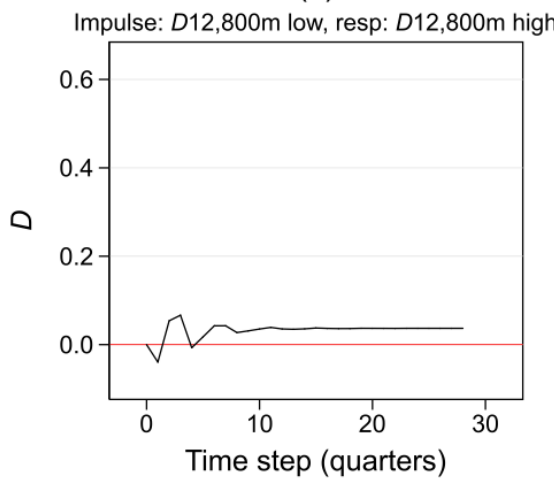

(b)

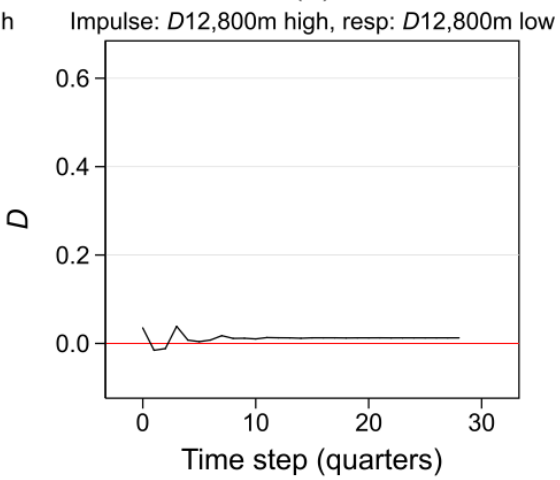

(d)

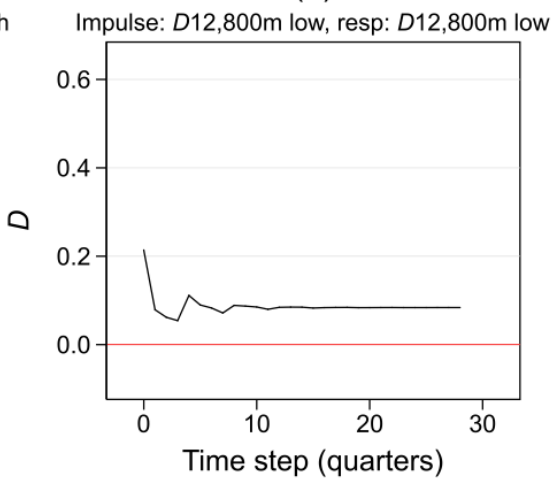

Fig. 8 Orthogonal impulse responses at macro scale $\varepsilon=12,800 \mathrm{~m}$ : (a) response of high value $D$ to impulse of high value $D$, (b) response of low value $D$ to impulse of high value $D$, (c) response of high value $D$ to impulse of low value $D$, and (d) response of low value $D$ to impulse of low value $D$ 
It was discussed earlier that the lead role in the dynamics of the neighborhood (micro) scale is assigned to the fractal dimension of high value clusters. This result is in line with the assumption of residential location models that the sorting process is initiated by the bids of wealthy households for high amenity areas and thus establishing high land value areas, followed by a filling-in of lower land values in the remaining locations. Furthermore, this agreement in the lead dynamics is found at the correct spatial scale, since the neighborhood or micro scale is typically associated with microeconomic behavior at relatively refined spatial scales. Conversely, the lead role in the dynamics of the citywide (macro) scale was assigned to the low value clusters. Recalling that this is a coarse scale, the property value morphology will resemble a smooth bid-rent gradient with low value clusters located at the urban periphery. The results thus suggest that dynamics are led by the low value clusters at the periphery, with high value clusters having to adjust to deviations from the equilibrium. This is interestingly consistent with Oikarinen (2005), who reports that prices in the periphery of Helsinki's metropolitan region diffuse towards - or Granger-cause - prices in the center. Lastly, the fact that the leads in each spatial scale tend to not adjust when they enter a state of disequilibrium, but will rather cause their counterparts to adjust, is characteristic of the non-stationary character of the system, and is in line with the gradual growth in fractal dimensions that was discussed in the previous section.

\subsection{Summary of the results}

Curves of fractal scaling behavior were estimated for spatial clusters of high and low residential property prices. These curves track the quarterly variation in the spatial morphology of high and low price $/ \mathrm{m}^{2}$ areas across Helsinki's metropolitan region from the second quarter of 1977 to the fourth quarter of 2011. The time series of fractal dimensions at indicative neighborhood ('micro') and citywide ('macro') scales were modeled with vector error correction specifications, exploring long run and short run joint behavior in the spatial morphologies of high and low price clusters.

Based on the results, summarized in Table 2, a number of points can be made. The point of departure is that the temporal behavior of housing prices is a concept that does not only relate to price levels, but also to their spatial morphology. Although this analysis does not provide information about the functional relationship between the two quantities, it nevertheless suggests that a policy discussion interested in short run and long run price behavior can revolve not only around the fluctuation of prices and their potential impacts, but also about the implications of fluctuations in the morphological characteristics of price clusters in urban space (the fractal geometry of which is just one aspect).

The co-integration analysis indicates that equilibrium-disequilibrium relationships between the quarterly morphologies of high and low price $/ \mathrm{m}^{2}$ clusters are present across spatial scales, but with differing specifics at each scale. At the micro (neighborhood) scale, high price/ $\mathrm{m}^{2}$ clusters are, in the long run, of consistently higher fractal dimension compared to low price $/ \mathrm{m}^{2}$ clusters, while this relation is reversed at the macro (citywide) scale. Short run adjustments following periods of disequilibria are also scale sensitive. The fractal behavior of high price $/ \mathrm{m}^{2}$ clusters leads the dynamics at the neighborhood scale, while low price $/ \mathrm{m}^{2}$ clusters lead at the citywide scale. The system's responses to exogenous shocks take about twice the time to stabilize at the neighborhood scale (20 quarters) compared to the citywide scale (eight to ten quarters). 
Table 2 Summary of the results ( $D$ denotes fractal dimension)

\begin{tabular}{|c|c|c|}
\hline & Neighborhood scale (200 m) & Citywide scale (12,800 m) \\
\hline $\begin{array}{l}\text { Fractal } \\
\text { geometry }\end{array}$ & $\begin{array}{l}D \approx 0.7 \text { for high price } / \mathrm{m}^{2} \text { clusters and } \approx 0.2 \text { for } \\
\text { low price } / \mathrm{m}^{2} \text { clusters. } \\
\text { Quarterly volatility } \approx+/-0.2 \text { in both price } / \mathrm{m}^{2} \\
\text { categories; } I(1) \text { non-stationary series. }\end{array}$ & $\begin{array}{l}D \approx 0.5 \text { for high price } / \mathrm{m}^{2} \text { clusters and } \approx 1.3 \text { for } \\
\text { low price } / \mathrm{m}^{2} \text { clusters. } \\
\text { Quarterly volatility } \approx+/-1 \text { for high price } / \mathrm{m}^{2} \\
\text { clusters and } \approx+/-0.3 \text { for low price } / \mathrm{m}^{2} \text { clusters; } \\
I(1) \text { non-stationary series. }\end{array}$ \\
\hline $\begin{array}{l}\text { Long run } \\
\text { equilibrium }\end{array}$ & $\begin{array}{l}D \text { of high price } / \mathrm{m}^{2} \text { clusters is approx. three } \\
\text { times that of low price } / \mathrm{m}^{2} \text { clusters. }\end{array}$ & $\begin{array}{l}D \text { of high price } / \mathrm{m}^{2} \text { clusters is approx. } 0.4 \text { times } \\
\text { that of low price } / \mathrm{m}^{2} \text { clusters. }\end{array}$ \\
\hline $\begin{array}{l}\text { Short run } \\
\text { adjustments }\end{array}$ & $\begin{array}{l}\text { Led by high price } / \mathrm{m}^{2} \text { clusters. } \\
\text { Low price } / \mathrm{m}^{2} \text { clusters adjust to short run } \\
\text { fluctuations of high price } / \mathrm{m}^{2} \text { clusters to restore } \\
\text { joint equilibrium. } \\
\text { High price } / \mathrm{m}^{2} \text { clusters do not adjust. }\end{array}$ & $\begin{array}{l}\text { Led by low price } / \mathrm{m}^{2} \text { clusters. } \\
\text { High price } / \mathrm{m}^{2} \text { clusters adjust to short run } \\
\text { fluctuations of low price } / \mathrm{m}^{2} \text { clusters to restore } \\
\text { joint equilibrium. } \\
\text { Low price } / \mathrm{m}^{2} \text { clusters do not adjust. }\end{array}$ \\
\hline $\begin{array}{l}\text { Orthogonal } \\
\text { impulse } \\
\text { responses }\end{array}$ & $\begin{array}{l}\text { High price } / \mathrm{m}^{2} \text { clusters have permanent effects. } \\
\text { Low price } / \mathrm{m}^{2} \text { clusters have near transient effects. } \\
\text { Effects stabilize in } 20 \text { quarters. }\end{array}$ & $\begin{array}{l}\text { High price } / \mathrm{m}^{2} \text { clusters have transient effects. } \\
\text { Low price } / \mathrm{m}^{2} \text { clusters have permanent effects. } \\
\text { Effects stabilize in eight to ten quarters. }\end{array}$ \\
\hline
\end{tabular}

The aforementioned aspects of the spatial economy are consistent with urban complexity's notion of synchronous multiscale processes in cities (Batty and Longley 1994; Batty 2007) and suggests that considering spatial economic behavior at more than one spatial and temporal scale at a time can reveal nontrivial information. At a more abstract level, it is also evident that the 'edge of chaos' notion (Packard 1988; Langton 1990; Farmer, cited in Waldrop 1994 and McMillan 2004) is relevant in urban economics since co-integration analysis can be regarded as one way to explore the temporal balance between chaotic and ordered conditions in key variables such as the spatial arrangement of residential real estate prices. These bring attention to the question of how the estimated equilibriumdisequilibrium relationships and their sensitivity to spatial scale relate to the processes described in the Alonso-Muth-Mills model and hedonic price theory. A first question would be whether certain spatial scales can be associated with the process of a particular model. A second question would be how the long run and short run relationship of high and low price $/ \mathrm{m}^{2}$ clusters relates to particular states, if any, of the two approaches.

Next, the findings support the idea that the typical view of cities as homogeneous areas of agglomeration benefits that decline with distance to the city center-or to amenity- or service-rich nodes of a multicentric system - should be perhaps revisited when spatially detailed policy analysis is of interest. The results suggest that, as far as residential property value is concerned, the benefits are in practice characterized by (a) a particularly granular morphology, which (b) differs across spatial aggregation scales, and (c) contains high and low price $/ \mathrm{m}^{2}$ agglomerations that are more complex than a multicentric view of cities and pulsate, drift, and change their spatial morphology in a highly volatile manner, although in the long run they can be regarded as stable.

Lastly, the results justify that increasing the level of spatial (i.e., more than one scale) and temporal (i.e., the relationship between long run and short run behavior) detail is important, as a large set of contemporary urban issues — ranging from smart, green cities through to climate-resilient and comprehensibly sustainable cities - involves impacts and autonomous or planned responses that involve a mix of phenomena at more than one spatial and temporal scale. Increasing the understanding 
of how price effects can be distributed in urban space in different ways depending on scale and price level is important for precise and effective decision making.

\section{Closing remarks}

A few points of attention should be noted concerning the interpretation of the modeled dynamics.

Firstly, the choice of aggregating the price observations into a $100 \mathrm{~m}$ square lattice, i.e., a choice of a certain shape to represent price clusters, has an influence on the measured fractal dimensions. An alternative option would be to use disaggregate point observations, but this does not offer clear advantages. On one hand, points are not represented in raster images as dimensionless entities but are drawn, too, as pixels of certain size and shape. Thus, the generated raster image, from which fractal dimensions are measured, will also contain assumptions about the shape and size of price clusters. If the objective is to represent price $/ \mathrm{m}^{2}$ points in as much a detailed manner as possible, then analyzing the physical footprint of properties would be logical, but the analysis would then relate to the morphology of the built environment and not to price clusters. On the other hand, the lattice offers a standardized measure of the way price/ $\mathrm{m}^{2}$ fills and varies across the urban area. Housing transactions are known to exhibit spatial autocorrelation (Dubin 1988), which means that the housing market behaves reasonably homogeneously inside an area of a certain size; the chosen aggregation preserves a sufficiently high spatial autocorrelation degree in the analyzed price variable while clearing the data from the difficult-to-interpret (for studies of large urban areas) and not free of errors variation of completely disaggregate observations. The standardized and homogeneous nature of an aggregated but very fine-resolution lattice and the fact that point observations are not trouble- or assumption-free meant that the chosen option, combined with a quarterly time step, represents an analytical setup better fitted for studying the spatial and temporal behavior of housing prices.

Next to the choice of cluster shape, the methodology of identifying clusters of high and low house prices also potentially influences the derived clusters. To check this, the analysis was repeated with a different cluster identification methodology (LISA clusters - Anselin 1995), different shape (hexagonal cells sized at approximately $150 \mathrm{~m}$ ) and by measuring total price rather than per $\mathrm{m}^{2}$ normalized price. The identified clusters differ only slightly between the Gi* and LISA methodologies and the results in this counterfactual case are largely the same. A second aspect is the comparison of clusters between quarters and the validity of probability thresholds used to identify the clusters of each separate quarter. This has been addressed first by adjusting the price levels to a common baseline, therefore making the high and low price $/ \mathrm{m}^{2}$ clusters in every quarter to refer to the same baseline level (i.e., the cluster algorithm is applied in multiple instances of a large 'crosssection') and second by employing the false discovery rate methodology (Caldas de Castro and Singer 2006) as a guard against misidentified clusters. While other methodologies might be applied to check the robustness of identified clusters, the abovementioned counterfactual tests suggest that the identified dynamics are not detrimentally sensitive to the choice of cluster identification methodology, as long as the prices are adjusted to a common baseline and the size of aggregation lattice matches the spatial scale at which the housing transactions operate.

Secondly, as each quarter contains transactions for both old and new properties, two main spatial processes are assumed to be mixed in the presented results: the growth of the housing stock; and spatial morphological fluctuations due to internal price adjustments of the existing stock. A first procedure to explore this issue would be to separate the fractal time series in trend and cyclical 
components. In this case, the trend would contain the gradual growth of fractal dimensions, associated with the growth of the housing stock. Conversely, the cyclical components would contain the influence of economic cycles and of internal adjustments. A second procedure would be to use cumulative patterns by stacking each quarter upon the previous ones. Although this is typical in urban morphology studies, it would overemphasize the trend (growth) component of the fractal dimensions and eliminate the information represented by the quarterly volatility. A third procedure would be to remove the transactions of new dwellings from each quarter. This, however, conflicts with the basic idea that new and old dwellings are both part of the search and bid process and both influence the formed prices in the housing market in each quarter.

The issue relates in fact to what part of the VEC equation refers to the modification of fractal geometry due to the physical expansion and densification of the housing stock, and what part refers to the adjustments of the fractal geometry of housing price clusters. By extension, it also relates to the relation of the trend and cyclical components to the idea of a joint equilibrium and short run adjustments in the spatial morphology of price $/ \mathrm{m}^{2}$ clusters. Trend and cycles typically relate to single time series, while VEC models focus on joint relationships. An assumption would be that trend terms in the long run equilibrium relationship (not included here) reflect the gradual growth of the housing stock, while the adjustment coefficients might relate to the internal adjustments of the housing stock and the influence of economic cycles. On the other hand, the non-stationarity of the co-integrated systems also reflects growth behavior. Additionally, the interpretation of trend terms in the levels and/or differences of the fractal dimensions would also need to be explored, but in this empirical sample the inclusion of such terms was not supported by specification tests. To address these issues, a study connecting the variation in the levels of prices with the variation in the spatial morphology of prices would be necessary, which would be an interesting extension of this study.

Thirdly, the analyzed housing prices are a sample of total transactions each year. This introduces biases in the analyzed spatial morphologies. It is alleviated by the fact that the inputs of the largest real estate brokers of Helsinki's metropolitan region are included in the sample, but the fact that the dataset does not capture the entire housing market is an important limitation. Furthermore, the rate of participation in this voluntary data reporting program may have annual variations, especially when the time frame of the analysis extends back to 1977, when participation was scarcer. Nevertheless, it is likely that this analysis does not suffer significantly from such biases, since the employed grid of average price $/ \mathrm{m}^{2}$ cells is a first measure to alleviate this problem, the 1997Q2 was specifically selected as the starting point as the number of observations becomes sufficient from that point in time, and the produced time series of spatial clusters does follow the factual urban development in Helsinki.

Fourthly, further examinations might consider the inclusion of exogenous variables, which is especially important for policy analysis. VEC models are specialized in the endogenous dynamics between non-stationary variables, but they are still VAR models at their core. VAR models are better geared in modeling exogenous effects in time series. A joint use of VAR and VEC models can therefore be recommended as a strategy for addressing both exogenous and endogenous effects.

Lastly, cross-scale characteristics need to be explored in more detail. Preliminary modeling of the fractal dynamics simultaneously at all spatial scales and with exogenous parameters has indicated notable cross-scale diffusions of endogenous and exogenous effects and Granger-causalities. A reasonable extension of this study would be to consider a single VEC model that includes dynamics of multiple spatial scales. This would encourage the use of more advanced aspects of VEC modeling. Similarly, there are strong indications that the identified price clusters are multifractal, that is, 
Votsis, A. J Geogr Syst (2017) 19(2):133-155. DOI 10.1007/s10109-017-0247-0 | Final draft version for self-archiving

composites of multiple sub-morphologies. A multifractal analysis framework would thus be beneficial. Ultimately, it would be of interest to associate the estimated fractals to mathematical ones. This would allow the drafting of a reference typology and the analytical modeling of the dynamics that have been examined here only numerically.

\section{References}

Alonso W (1964) Location and land use. Harvard University Press, Cambridge [MA]

Anas A (2013) A summary of the applications to date of RELU-TRAN, a microeconomic urban computable general equilibrium model. Environ Plann B 40(6): 959-970

Anselin L (1995) Local indicators of spatial association-LISA. Geogr Anal 27(2): 93-115

Batty M (2007) Cities and complexity: Understanding urban dynamics with agent-based models, cellular automata, and fractals. MIT Press, Cambridge [MA]

Batty M, Longley P (1994) The fractal city: A geometry of form and function. Academic Press, London

Brueckner JK (2011) Lectures in urban economics. MIT Press, Cambridge [MA]

Brueckner JK, Thisse J-F, Zenou Y (1999) Why is central Paris rich and downtown Detroit poor? An amenity based theory. Eur Econ Rev 43(1): 91-107

Caldas de Castro M, Singer BH (2006) Controlling the false discovery rate: A new application to account for multiple and dependent test in local statistics of spatial association. Geogr Anal 38(2): 180-208

DiPasquale D, Wheaton WC (1996) Urban economics and real estate markets. Prentice Hall, New Jersey

Dubin R (1988) Estimation of regression coefficients in the presence of spatially autocorrelated error terms. Rev Econ Stat 70(3): 466-474

Echenique MH, Grinevich V, Hargreaves AJ, Zachariadis V (2013) LUISA: A land-use interaction with social accounting model; presentation and enhanced calibration method. Environ Plann B 40(6): 1003-1026

Engle RF, Granger CWJ (1987) Co-integration and error correction: Representation, estimation and testing. Econometrica 55(2): 251-276

Ettema D (2011) A multi-agent model of urban processes: Modelling relocation processes and price setting in housing markets. Computers, Environment and Urban Systems 35(1): 1-11

Filatova T, Bin O (2013) Changing climate, changing behavior: Adaptive economic behavior and housing market responses to changing flood risks. In Kamisnki B, Kolloch G (eds) Advances in social simulation. Springer, Berlin, pp 249-258

Filatova T, Parker D, van der Veen A (2009) Agent-based urban land markets: Agent's pricing behavior, land prices and urban land use change. JASSS-J Artif Soc S 12(1): 1-31

Frankhauser P (1988) The fractal approach. A new tool for the spatial analysis of urban agglomerations. Population 10(1): 205-240 
Votsis, A. J Geogr Syst (2017) 19(2):133-155. DOI 10.1007/s10109-017-0247-0 ～Final draft version for self-archiving

Getis A, Ord JK (1992) The analysis of spatial association by use of distance statistics. Geogr Anal 24(3): 189-206

Glaeser EL, Gottlieb JD (2009) The wealth of cities: Agglomeration economies and spatial equilibrium in the United States. J Econ Lit 47(4): 983-1028

Ioannides YM (2013) From neighborhoods to nations: The economics of social interactions. Princeton University Press, Princeton [NJ]

Johansen S (1988) Statistical analysis of cointegrating vectors. Journal of Economic Dynamics and Control 12(2): 231-254

Johansen S (1991) Estimation and hypothesis testing of cointegration in Gaussian vector autoregressive models. Econometrica 59(6): 1551-1580

Johansen S (1995) Likelihood-based inference in cointegrated vector autoregressive models. Oxford University Press, Oxford

Kenny G (1999) Modelling the demand and supply sides of the housing market: Evidence from Ireland. Econ Model 16(3): 389-409

Langton CG (1990) Computation at the edge of chaos: Phase transitions and emergent computation. Physica D 42(1): 12-37

Lütkepohl H (2005) New introduction to multiple time series analysis. Springer-Verlag, Berlin.

Lütkepohl H, Krätzig M (2004) Applied time series econometrics. Cambridge University Press, Cambridge [UK]

Mandelbrot B (1967) How long is the coast of Britain? Statistical self-similarity and fractional dimension. Science 156(3775): 636-638

Mandelbrot B (1982) The fractal geometry of nature. W. H. Freeman and Co., New York

McMillan E (2004) Complexity, organizations and change. Routledge, London and New York

Mills ES (1967) An aggregative model of resource allocation in a metropolitan area. American Economic Review 57(2): 197-210

Muth RF (1969) Cities and housing. Chicago, University of Chicago Press [IL]

Oikarinen E (2005) The diffusion of housing price movements from centre to surrounding areas. Discussion Paper No. 979, The Research Institute of the Finnish Economy (ETLA).

Oikarinen E (2014) Is urban land price adjustment more sluggish than housing price adjustment? Empirical evidence. Urban Stud 51(8): 1686-1706

Ord JK, and Getis A (1995) Local spatial autocorrelation statistics: Distributional issues and an application. Geogr Anal 27(4): 286-306

O’Sullivan A (2000) Urban economics. McGraw-Hill, New York

Packard N (1988) Adaptation toward the edge of chaos. Center for Complex Systems Research, University of Illinois at Urbana-Champaign, Urbana [IL]

Rosen S (1974) Hedonic prices and implicit markets: Product differentiation in pure competition. J Polit Econ 82(1): 34-55 
Votsis, A. J Geogr Syst (2017) 19(2):133-155. DOI 10.1007/s10109-017-0247-0 | Final draft version for self-archiving

Saarinen L (2013) A cointegration analysis of house price formation in the Helsinki metropolitan area. Master's thesis, University of Helsinki

Sheppard S (1999) Hedonic analysis of housing markets. In Cheshire P, Mills ES (eds) Handbook of regional and urban economics. Elsevier, Amsterdam, pp 1595-1635

Thomas I, Frankhauser P, Biernacki C (2008) The morphology of built-up landscapes in Wallonia (Belgium): A classification using fractal indices. Landscape Urban Plan 84(2): 99-115

Thomas I, Frankhauser P, Frenay B, Verleysen M (2010) Clustering patterns of urban built-up areas with curves of fractal scaling behavior. Environ Plann B 37(5): 942-954

Thomas I, Frankhauser P, Badariotti D (2012) Comparing the fractality of European urban neighbourhoods: Do national contexts matter? J Geogr Syst 14(2): 189-208

Votsis A, Perrels A (2016) Housing prices and the public disclosure of flood risk information: A difference-in-differences analysis in Finland. J Real Estate Finan Econ 53(4): 450-471

Wegener M (1994) Operational urban models: State of the art. J Am Plann Assoc 60(1): 17-28.

Wegener M (2008) SASI Model Description. Working Paper 08/01. Spiekermann \& Wegener Stadt- und Regionalforschung, Dortmund http://www.spiekermannwegener.de/mod/pdf/AP_0801.pdf

Waldrop MM (1994) Complexity. Penguin Books, New York 